\title{
Diagnosis and clinical associations of zinc depletion following bone marrow transplantation
}

\author{
A Papadopoulou, K Nathavitharana, M D Williams, P J Darbyshire, I W Booth
}

\begin{abstract}
Following the emergence of biochemical zinc deficiency after bone marrow transplantation, the clinical value of plasma alkaline phosphatase activity as an early indicator of biochemical zinc depletion was investigated in this group of patients. Serial measurements of plasma zinc and alkaline phosphatase activities in 28 consecutive children (median age 8.7 years; 16 males) undergoing bone marrow transplantation were carried out and clinical associations recorded. A significant fall in plasma zinc occurred after the bone marrow transplant, and 19 children developed biochemical zinc deficiency $(\mathrm{Zn}<11$ $\mu \mathrm{mol} / \mathrm{l})$ at a median of 7 days following the transplant. Zinc depletion was more common in younger patients and in children with diarrhoea. A positive correlation was found between plasma zinc and alkaline phosphatase activities. Zinc depleted patients had more febrile episodes of longer duration and were more likely to have a positive blood culture. Haemopoetic recovery was not affected by zinc deficiency. Following zinc supplementation, alkaline phosphatase showed a significant increase. The sensitivity of a low alkaline phosphatase as a screening test for biochemical zinc deficiency was $83 \%$, with a specificity of $86 \%$. Low alkaline phosphatase activity following bone marrow transplant is an indication for zinc supplements.

(Arch Dis Child 1996; 74: 328-331)
\end{abstract}

Keywords: zinc, alkaline phosphatase, sepsis, diarrhoea, bone marrow transplantation.

Zinc is a cofactor in a number of metalloenzymes involved in nucleic acid synthesis ${ }^{1}$ and the maintenance of normal immunological function. ${ }^{2}$ Clinical zinc deficiency is now rare in children receiving nutritional support, as the parenteral and enteral nutrition regimens contain zinc. We were therefore surprised to find that biochemical zinc deficiency was occurring in a relatively new group of children: those receiving nutritional support following bone marrow transplantation.

The clinical manifestations of zinc deficiency (anorexia, rash, alopecia, diarrhoea, infections, and failure to thrive) are common following bone marrow transplantation, and therefore the frequency of clinical zinc deficiency in these children is difficult to assess. Accurate biochemical assessment of zinc status is also difficult in clinical practice, as the gold standard is an estimation of concentrations in hair or in tissue such as liver, rectal mucosa, leucocytes, or erythrocytes. It has been suggested that the plasma activity of alkaline phosphatase (a zinc metallo-enzyme) may be a useful alternative index of zinc status. $^{3}$ Although this possibility has often been cited, we are not aware of any previous study to test its validity on the basis of longitudinal measurements of both alkaline phosphatase activities and plasma zinc. The aims of this study were therefore to assess the frequency and clinical associations of biochemical zinc depletion in children undergoing bone marrow transplantation, and to examine the value of serum alkaline phosphatase activity as an index of biochemical zinc deficiency.

\section{Methods}

SUBJECTS

Twenty eight consecutive patients undergoing bone marrow transplantation were prospectively studied. The characteristics of the patients are shown in the table.

\section{PROCEDURES}

Anthropometry and biochemistry

Anthropometry (weight, mid-arm circumference, skinfold thickness measurements), and plasma zinc were measured weekly and alkaline phosphatase activities twice weekly. The conditioning regimens used in this hospital have been described previously. ${ }^{4}$ The study protocol was approved by the research ethics committee of South Birmingham Health Authority.

Characteristics of the patients

\begin{tabular}{|c|c|}
\hline Median age (years) & 9 (range $0 \cdot 9-19 \cdot 3$ ) \\
\hline \multicolumn{2}{|l|}{ Sex } \\
\hline Male & 16 \\
\hline Female & 12 \\
\hline \multicolumn{2}{|l|}{ Diagnoses } \\
\hline \multicolumn{2}{|l|}{ Acute lymphoblastic/chronic } \\
\hline myeloblastic leukaemia & 17 \\
\hline Solid tumours & 2 \\
\hline Aplastic anaemias & 3 \\
\hline$\beta$-Thalassaemia major & 3 \\
\hline Sickle cell anaemia & 1 \\
\hline Wiskott-Aldrich syndrome & 1 \\
\hline \multicolumn{2}{|l|}{ Type of bone marrow transplant } \\
\hline Allogeneic & 25 \\
\hline Autologous & 3. \\
\hline \multicolumn{2}{|l|}{ Nutritional support } \\
\hline Parenteral nutrition & 13 \\
\hline Enteral nutrition & 8 \\
\hline No support & 7 \\
\hline \multicolumn{2}{|l|}{ Conditioning } \\
\hline $\begin{array}{l}\text { Cyclophosphamide }+ \text { total body } \\
\text { irradiation }\end{array}$ & 12 \\
\hline Campath + busulphan + cyclo- & \\
\hline phosphamide & 11 \\
\hline $\begin{array}{l}\text { Idarubicin + total body irradiation }+ \\
\text { cyclophosphamide }\end{array}$ & \\
\hline $\begin{array}{l}\text { cyclophosphamide } \\
\text { Melphelan }\end{array}$ & $\begin{array}{l}2 \\
3\end{array}$ \\
\hline $\begin{array}{l}\text { Median duration of hospital stay following } \\
\text { bone marrow transplant (days) }\end{array}$ & 29 (range $17-122)$ \\
\hline
\end{tabular}

Correspondence to: Dr A Papadopoulou, Athens Children's Hospital, 'P \& A Kyriakou', Thivon \& Levadias, Athens 115 27,

Accepted 22 December 1995 


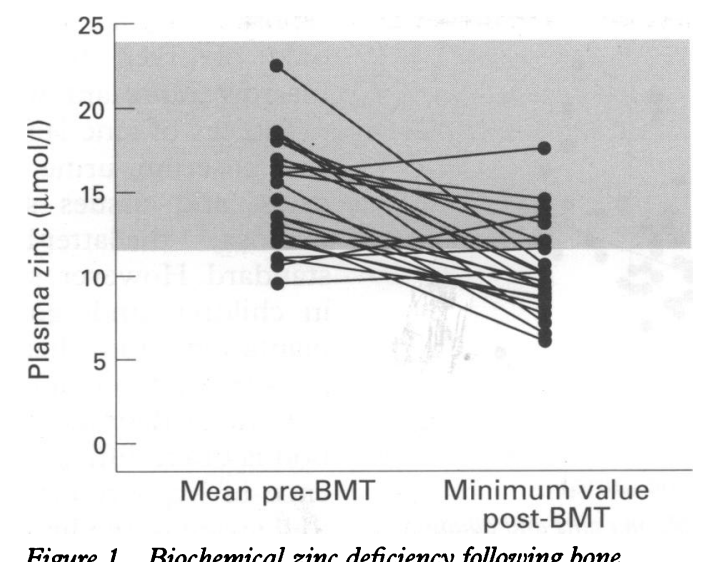

Figure 1 Biochemical zinc deficiency following bone marrow transplantation. A significant fall in plasma zinc was observed in children following the transplant $(p<0.001)$. The hatched area represents the laboratory reference range.

Informed consent was obtained from the patients or their parents.

\section{Documentation of fever}

The occurrence of febrile episodes (temperature more than $38^{\circ} \mathrm{C}$ for more than one day) was recorded. Each was investigated according to the bone marrow transplant unit protocol. ${ }^{4}$

\section{NUTRITIONAL SUPPORT}

Twenty one patients received nutritional support: 13 received parenteral nutrition for a median duration of 23 days, and eight received supplementary enteral nutrition for a median duration of 15 days. Indications for nutritional support were: malnutrition on admission (weight for height $\mathrm{Z}$ score $<-1$ ); weight loss post transplant of more than $5 \%$ of admission weight; or a decrease in mid-arm circumference of more than $10 \%$.

\section{Parenteral nutrition}

As the fluid volume available for parenteral

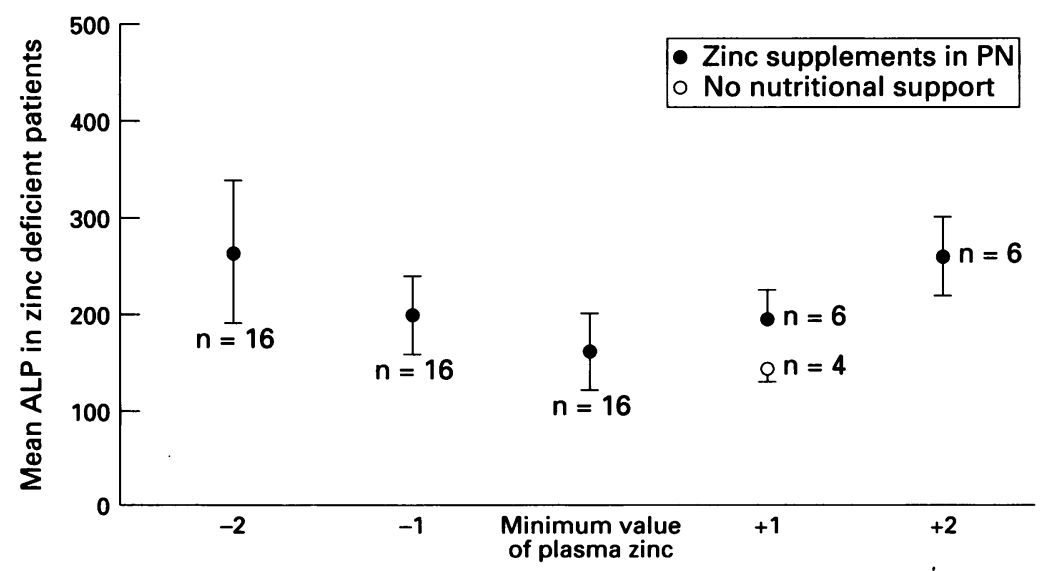

Week before and after minimum value of plasma zinc recorded

Figure 2 Changes in alkaline phosphatase activity ( $A L P, U /)$ following bone marrow transplantation. A significant fall in ALP activities was observed following the transplant, one week before the development of biochemical zinc depletion ( $p=0.001)$; an even more significant fall was observed at the time of the low zinc assays $(p<0.001)$. Significant increases of $A L P$ activity were observed one week and two weeks after zinc supplementation of parenteral nutrition (PN) ( $p=0.04$ and $p=0.0007$, respectively). nutrition had to be kept to a minimum because of concurrent infusions for other purposes, a high nitrogen parenteral solution (Hyperamine-30; Braun Medical) ${ }^{5}$ was used. Zinc was provided as Ped-El ( $4 \mathrm{ml} / \mathrm{kg} / \mathrm{d})$ in infants weighing less than $10 \mathrm{~kg}$ (which provided 0.6 $\mu \mathrm{mol} / \mathrm{kg} / \mathrm{d}$ of elemental zinc) and Addamel $(0.2 \mathrm{ml} / \mathrm{kg} / \mathrm{d})$ in children over $10 \mathrm{~kg}$ body weight (which provided $0.4 \mathrm{mmol} / \mathrm{kg} / \mathrm{d}$ of elemental zinc).

\section{Supplementary enteral nutrition}

Enteral nutrition was provided as overnight feeding through a nasogastric tube. The aim was to supplement the oral intake and to provide all the energy requirements by this route. Feeds used were Nutrison Paediatric (Nutrison, Cow \& Gate) in children weighing $<20 \mathrm{~kg}$ and Fortisip (Fortisip, Cow \& Gate) for older children. Energy supplements (glucose polymer and long chain triglyceride emulsion) were added to the standard enteral feeds as necessary. In children with diarrhoea, a peptide based feed (Peptide, SHS) was given. Each of these formulas provided $1 \mathrm{mg}$ of elemental zinc in $100 \mathrm{ml}$.

\section{Results}

A significant fall in plasma zinc was observed following bone marrow transplantation. The mean (SD) plasma zinc concentration in the 10 days before bone marrow transplant, and the minimum value observed following bone marrow transplant, were $14.6(3.3)$ and 10.4 $(2 \cdot 8) \mu \mathrm{mol} / 1$ respectively $(\mathrm{p}<0.001$; fig 1$)$. Nineteen of the 28 children became biochemically zinc deficient (plasma zinc $<11$ $\mu \mathrm{mol} / \mathrm{l})$ at a median of seven days after the transplant (range $8 \mathrm{~d}$ before to $27 \mathrm{~d}$ after). Eight of the 19 zinc deficient children were not receiving any nutritional support at the time they developed biochemical zinc depletion. In the remaining 11 patients, a low zinc was first observed at a median of six days following the introduction of nutritional support (enteral nutrition $5 \mathrm{~d}$; parenteral nutrition $6 \mathrm{~d}$ ). Children who developed biochemical zinc deficiency were younger than children who did not: median age $7 \cdot 3$ years, range $0.9-16.9, v 11.6$ years, range $5 \cdot 3-19 \cdot 3$, respectively $(p=0 \cdot 02)$. However, zinc deficiency was unrelated to weight loss, type of nutritional support, conditioning regimen, indication for bone marrow transplant, or the presence of hypoalbuminaemia (mean plasma albumin at the presentation of zinc deficiency was $34 \mathrm{~g} / \mathrm{l}$ ).

Febrile episodes occurred more often during biochemical zinc depletion: 18 of the 41 low zinc assays recorded in 18 zinc depleted patients were associated by febrile episodes, compared with only five of a total of 82 normal zinc assays $(p<0.001)$. In addition, six out of the 41 low zinc assays were associated with positive blood cultures compared with only four of the 82 normal zinc assays $(p<0.03)$. Furthermore, febrile episodes were longer in children with low plasma zinc: mean (SD) days of fever $5 \cdot 2(5 \cdot 2)$ $v 1.7(2.9)$ respectively $(\mathrm{p}=0.05)$. 


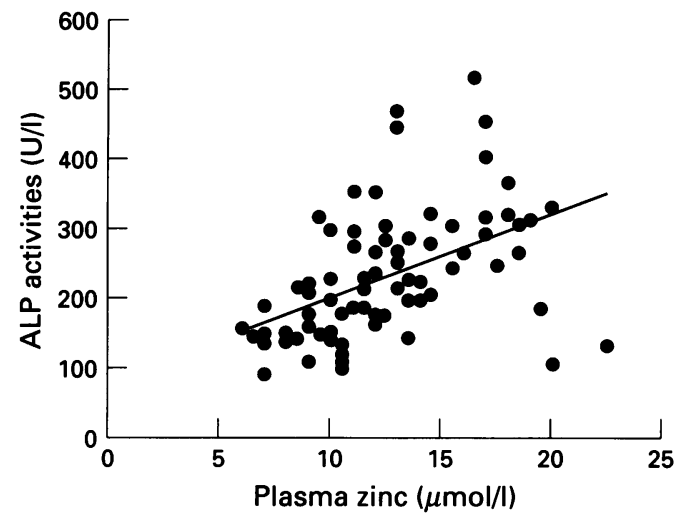

Figure 3 Correlation between plasma zinc and alkaline phosphatase activity. A significant correlation between alkaline phosphatase activity and plasma zinc was found $(r=0.47 ; p<0.001)$.

Diarrhoea predisposed to biochemical zinc deficiency. Mean (SD) concentrations of plasma zinc in children with diarrhoea and in those without were $8.6(1.9)$ and $12 \cdot 1(2 \cdot 6)$ $\mu \mathrm{mol} / 1$ respectively $(\mathrm{p}=0.001)$.

Zinc deficiency was not associated with a delay in bone marrow recovery. Haemopoietic recovery (lymphocyte count $>10^{3}$ ) was observed at a median of 17 days (range 4-27) in zinc depleted patients and of 17 days (range 13-89) in patients with normal zinc.

Biochemical zinc depletion was associated with a significant fall in plasma alkaline phosphatase: mean (SD) values of alkaline phosphatase activity two weeks before the first low zinc assays was 265 (74) U/l; one week later it was $202(41) U / 1(p=0.001)$; and within the period of low zinc it was 166 (37) $U / 1$ $(p<0.001)$ (fig 2). A significant difference was found between the mean plasma alkaline phosphatase activity in patients who developed zinc depletion and in those with normal zinc following bone marrow transplantation: mean (SD), 187 (31) and 255 (64) U/1, respectively $(p=0 \cdot 001)$. Consistent with the zinc dependent nature of the enzyme, alkaline phosphatase activities correlated positively with plasma zinc $(r=0.47 ; \mathrm{p}<0.001$; fig 3$)$.

The provision of zinc supplements ( 300 $\mu \mathrm{g} / \mathrm{d})$ in parenteral nutrition to six children with low serum zinc led to a significant increase in alkaline phosphatase activity: mean (SD) activity at the introduction of supplements was $154(24) \mathrm{U} / 1$; two weeks later it was $243(20) \mathrm{U} / 1(\mathrm{p}<0 \cdot 001)$ (fig 2).

Three of the 28 patients developed deranged liver function following bone marrow transplantation and were excluded from the analyses used to assess the reliability of alkaline phosphatase activity as a screening test for zinc depletion. In the remaining patients, a low alkaline phosphatase $(<200 \mathrm{U} / \mathrm{l})$ had a sensitivity of $83 \%$ and a specificity of $86 \%$ in detecting biochemical zinc deficiency.

\section{Discussion}

In this study we showed that biochemical zinc deficiency was common after bone marrow transplantation and occurred in $67 \%$ of children, particularly in the younger patients. This finding is not consistent with a recent report in adults, where low plasma zinc was only observed before and not after bone marrow transplantation. ${ }^{6}$

Indices of zinc status include estimation of zinc in serum, urine, hair, leucocytes, erythrocytes, and tissues such as liver and rectal mucosa, ${ }^{3}$ the latter being regarded as the gold standard. However, such assays are impractical in children undergoing bone marrow transplantation, and therefore the estimation of plasma zinc remains the most widely used option for defining zinc status. Its interpretation is often difficult, ${ }^{8}$ particularly in the presence of hypoproteinaemia. ${ }^{9}$ Although we are well aware of the limitations of plasma zinc we did not feel that assay of tissue zinc was ethically appropriate here. We were able to show, however, that a functional index of zinc status (low alkaline phosphatase activity) was a valid indicator of zinc deficiency. This view was supported by our observation, consistent with other reports, ${ }^{10}$ that zinc supplementation was associated with a significant rise in alkaline phosphatase activity. Cavan et al ${ }^{11}$ also showed significant positive correlations between plasma zinc and alkaline phosphatase activities, whereas no correlations were found between either hair and plasma zinc or hair zinc and plasma alkaline phosphatase activities. Gibson et al ${ }^{12}$ reported normal values of alkaline phosphatase activity in children with normal plasma zinc but low hair zinc and impaired growth. In that study, following 12 months of oral zinc supplementation a significant change in height was noted, although there was no increase in hair zinc. Low hair zinc concentrations show chronic zinc deficiency but standardised techniques for measurement have to be used, and environmental factors such as season need to be taken into account. In our study we showed that alkaline phosphatase is a rapid and widely available early indicator of biochemical zinc deficiency, with high sensitivity and specificity. Furthermore, all biochemical laboratories can measure alkaline phosphatase, whereas zinc assays are provided supraregionally and are slower. Plasma alkaline phosphatase costs $19 \%$ of the cost of plasma zinc and the results are available within a few hours.

Zinc deficiency following bone marrow transplantation is probably the result of a combination of low intake, impaired absorption, and excessive loss from the gastrointestinal tract. In our patients, biochemical zinc deficiency was significantly linked with diarrhoea. In a recent study in children with diarrhoea, faecal zinc losses were found to correlate significantly with faecal weight and a negative correlation was found between plasma concentrations of zinc and faecal zinc losses. ${ }^{13}$

The clinical impact of zinc depletion in children undergoing bone marrow transplantation is unclear. Anorexia, negative nitrogen balance, weight loss, and predisposition to infections are common complications, usually attributed to the use of immunosuppressive agents and total body irradiation. It is therefore difficult to assess to what extent these problems are caused by zinc deficiency. Zinc has been 
reported to promote growth in severely malnourished children. ${ }^{14}$ Furthermore, a community based study in Guatemalan children showed that zinc supplementation is associated with changes in indices of body composition rather than height and weight gain. ${ }^{11}$ Studies in experimental animals suggest that zinc depletion may be associated with a delayed wound healing process. ${ }^{15}$ In the human, manifestations of zinc deficiency include poor tissue healing, dermatitis, impairment of neuropsychological function, ${ }^{16}$ and impaired haematopoiesis. ${ }^{17}$ Therefore, the postulated benefits of zinc repletion following bone marrow transplantation may include improvement in haematopoietic recovery and tissue repair. However, in this study zinc depletion did not seem to delay the bone marrow recovery.

Recent studies have reported that low zinc predisposes to an increased susceptibility to infection. ${ }^{1819}$ In this study, febrile episodes occurred more often and were longer in children with biochemical zinc depletion. Immunological abnormalities (for example, lymphopenia, depressed $T$ cell mitogenic response, and so on) have been described in a patient receiving parenteral nutrition with inadequate zinc supplementation with correction after zinc repletion. ${ }^{20}$ Furthermore, zinc supplementation has been shown to correct some of the observed immunological abnormalities in children with protein-energy malnutrition. ${ }^{21}$ It is therefore important in patients who are already immunosuppressed and at increased risk of developing severe infections to recognise and correct zinc deficiency promptly.

In conclusion, biochemical zinc deficiency is common following bone marrow transplantation and it has adverse clinical sequelae. A reduced alkaline phosphatase is a reliable screening test of zinc deficiency and indicates the need for zinc supplements following bone marrow transplantation in young patients who develop diarrhoea.
1 Wu FYH, Wu CW. Zinc in DNA replication and transcription. Annu Rev Nutr 1987; 7: 251-72.

2 Keen CL, Gershwin ME. Zinc deficiency and immune function. Annu Rev Nutr 1990; 10: 415-31.

3 Arnaud J, Chappuis P, Jaudon MC, Bellanger J. Nutritional biological markers of deficiencies of zinc, copper and selenium. Ann Biol Clin 1993; 51: 589-604.

4 Papadopoulou A, Nathavitharana KA, Williams MD, et al. Diarrhoea and weight loss following bone marrow transplantation in children. Pediatr Hematol Oncol 1994; 11: 601-11.

5 Papadopoulou A, Pandya S, Ball P, et al. Efficacy of a new, high nitrogen parenteral solution (Hyperamine-30) in high nitrogen parenteral solution (Hyperamine-30) in children undergoing bone marro

6 Antilla HM, Salo MS, Kirvela O, et al. Serum trace element concentrations and iron metabolism in allogenic bone marrow transplant recipients. Ann Med 1992; 24: 55-9.

7 Ruz M, Cavan KR, Bettger WJ, Gibson RS. Erythrocytes, erythrocyte membranes, neutrophils and platelets as biopsy materials for the assessment of zinc status in humans. Br F Nutr 1992; 68: 515-27.

8 Golden MHN, Golden BE, Harland PSEG, Jackson AA Zinc and immunocompetence in protein-energy malnutrition. Lancet 1978; i: 1226-7.

9 Puri P, Kenny D, Guiney EJ. The need to consider changes in plasma proteins in interpreting postoperative plasma zinc changes. Clin Chim Acta 1981; 110: 341-4.

10 Walravens PA, Hambidge KM, Koepfer DM. Zinc supplementation in infants with a nutritional pattern of failure to mentation in infants with a nutritional pattern of failure to thrive: a doub

11 Cavan KR, Gibson RS, Grazioso CF, et al. Growth and body composition of periurban Guatemalan children in relation to zinc status: a cross sectional study. Am $\mathcal{f}$ Clin Nutr 1993; 57: 334-43.

12 Gibson RS, Vanderkooy PDS, MacDonald AC, Goldman A, Ryan BA, Berry M. A growth-limiting, mild zincdeficiency syndrome in some Southern Ontario boys with low height percentiles. Am f Clin Nutr 1989; 49: 1266-73.

13 Castillo-Duran C, Vial P, Uauy R. Trace mineral balance during acute diarrhoea in infants. $\mathcal{F}$ Pediatr 1988; 113: 452-7.

14 Prentice A. Does mild zinc deficiency contribute to poor growth performance? Nutr Rev 1993; 51: 268-70.

15 Groundwater W, Macleod IB. The effect of systemic zinc supplement on the strength of healing incised wounds in supplement on the strength of healing inci
normal rats. Br $\mathcal{f}$ Surg 1970; 57: 222-5.

16 Sandstead $\mathrm{HH}$. Zinc deficiency. A public health problem? Am $\mathcal{F}$ Dis Child 1991; 145: 853-9.

17 Aggett PJA. Trace elements in human health. Practitioner 1984; 228: 935-8.

18 Gershwin M, Beach RS, Hurley LS. Zinc. In: Nutrition and immunity. New York: Academic Press, 1985: 405.

19 Hambidge KM, Casey CE, Krebs NF. Zinc. In: Mertz W ed. Trace elements in human health and animal nutrition, 5th ed. New York: Academic Press, 1986: 1-137.

20 Allen JI, Perri RT, McClain CJ, Kay NE. Alternatives in human natural killer cell activity and monocyte cytotoxicity induced by zinc deficiency. $₹$ Lab Clin Med 1983; 102: 577-89.

21 Castillo-Duran C, Heresi G, Fisberg M, Uauy R. Controlled trial of zinc supplementation during recovery from malnutrition: effects on growth and immune function. $A m$ f Clin Nutr 1987; 45: 602-8. 